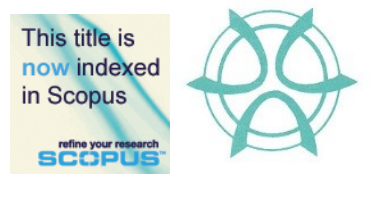

PLANNING MALAYSIA:

Journal of the Malaysian Institute of Planners

VOLUME 18 ISSUE 2 (2020), Page 85 - 96

\title{
3D GEOSPATIAL TECHNIQUE IN ANALYSING THE MALAY HERITAGE BUILDING STRUCTURES
}

\author{
Ahmad Afiq Aiman Abdullah ${ }^{1}$, Norzailawati Mohd Noor ${ }^{2}$, Alias \\ Abdullah ${ }^{3}$, Maisarah $\mathrm{Ali}^{4} \&$ Muhammad Hadi Mustafa ${ }^{5}$ \\ ${ }^{1,2,3,5}$ Kulliyyah of Architecture and Environmental Design \\ ${ }^{4}$ Kulliyyah of Engineering \\ INTERNATIONAL ISLAMIC UNIVERSITY MALAYSIA
}

\begin{abstract}
Malay buildings are synonym with the unique design of full decorative on motive, unique façade design, and roof structured. Most of heritage buildings had been demolished and left out without proper documentation and preserving the building database. Latest mapping systems provide an efficient technique for acquiring dense point clouds in analysing the building structure. This paper aim to explore on the technique acquiring the data for distribution and the façade of building with the Malay architecture design using the laser scanning. Data acquisition was taken for two sites which are Kota Bharu, Kelantan and Alor Setar, Kedah with two different techniques were applied for data collection which are TLS and MLS method. Both methods had succeed in capturing the detail of the features and building in the study area in point cloud form and the analysis of the data was able to analysed on the classification and identification of the Malay building elements and features which still preserved Malay design at the facade and roof element in the study area. As the final results and findings, there were big gaps between the building which still preserved the Malay design in the study area where Kota Bharu recorded 71 units building meanwhile Alor Setar only 15 buildings. The results showed that, most of the Traditional Malay building still being preserved in Kota Bharu compared to Alor Setar.
\end{abstract}

Keywords: Heritage, Malay House, Laser Scanning, 3D geospatial

${ }^{1}$ Postgraduate Student at International Islamic University Malaysia. Email: irme.aiman@gmail.com 
Ahmad Afiq Aiman Abdullah, Norzailawati Mohd Noor, Alias Abdullah, Maisarah Ali, Muhammad Hadi Mustafa

3D Geospatial Technique in Analysing the Malay Heritage Building Structures

\section{INTRODUCTION}

Laser scanning technology is one of the widely used technology in surveying and geospatial information and data collection since early 1990s (Beraldin et al. 2010). The use of the laser scanning is not just bind for surveying only, but also widely spread towards much more field of study and data collection, such as heritage studies, urban design and urban planning studies, crime scenes investigation, and even for construction industries. Most of this field of studies require the most effective method for the data acquisition, analysis and importantly for data storage system. The primitive method by using drawing, or $2 \mathrm{D}$ database are a bit challenging and required a lot of work and the data storage system and analysis were fragile and lead to confusing in understanding the data form and function. According to Guan et al. (2015), the automatic 3D scene analysis using Light Detection and Ranging (LiDAR) point's clouds has been a challenging task in research fields of photogrammetry, remote sensing, computer vision and robotics for the past 10 years back. Compared to field surveys and photogrammetry technique, the laser scanning captures very highly accurate 3D points clouds with a high point high point density in a relatively short amount of time (Haala et al., 2008; Chehata et al., 2009; Ussyshkin 2009). Today, the method of data acquisition for points cloud dataset can be varied as the development of the technology, such as using the terrestrial laser scanning (TLS), airborne laser scanning (ALS) and mobile laser scanning (MLS) (Guan et al.,2015). Airborne laser scanning usually used scanning large-scale area of interest with relative low point density and for MLS and TLS technique applied for dense and accurate 3D scene analysis and documentation especially in the context of urban areas and focused structure. This paper intends to document the process and technique used in data acquisition in recognizing the Malay heritage building structure using different laser scanning technique which are terrestrial laser scanning (TLS) and mobile laser scanning (MLS) for two different studies which are in Kota Bharu and Alor Setar.

\section{Laser Scanning Application in Heritage Conservation}

The demand and the importance of data acquisition with high precision and accuracy in various fields such as, heritage, archaeology, and cultural landscapes have led to the development in the application and tool in data collection (Haddad, 2011). The capability of the instrument or tools to provide large amount of data and high performances especially the capability for single operator can run the survey or data collection process in short time are the main value added in selection of the technique during data collection (Nesi, 2013). Even though the technology is only a tool to ease the research progress, the capability of technology to bring up the hidden information that are simply not visible to the naked eyes was very helpful in a research. Laser scanner is a tool which is able to measure the position of thousands of points in the space that will define the 
PLANNING MALAYSIA

Journal of the Malaysia Institute of Planners (2020)

surface of the scanned feature (Nesi, 2013). According to Grussenmeyer et al. (2016), laser scanning was an active, fast and automatic technique for data acquisition using laser light for measuring without any contact in a dense regular pattern, 3D coordinates of points on surfaces. The laser scanner emits and receive their own electromagnetic radiation which can be categorized as active data collection compared to photography which rely on reflected ambient or artificial light which can be categorized as passive data collection (Nesi, 2013). The output from the laser scanning is to produce the high density of point cloud database which reflect the surface of the measured or scanned object. Point clouds was the result from the scanning process which consist of millions of points placed in the space according to the $\mathrm{XYZ}$ coordinates that can be used to recreate the $3 \mathrm{D}$ model of the scanned objects. For the paper, the use of the data point cloud was focused to analyse the historical element which associated with the Malay design using the terrestrial laser scanning and mobile laser scanning in order to integrates the geospatial approach in heritage and conservation field of study.

\section{Terrestrial Laser Scanning}

The Terrestrial Laser Scanner (TLS) was effective in recording and documenting due to its capability providing better spatial information of a building or structure in complex 3D scenes in a short period of time. The data acquired using TLS via laser beam that travel towards the area being scanned and back to the laser lenses consist of 3D coloured point clouds data with accuracies range from millimetres to centimetres (Lee, 2013). This data contains of millions of points with geometric coordinates (X, Y and Z) can be used to give a realistic impression of a building or structure for users to interactively navigate the viewpoint around it, viewing base on all the position and the angles required.

\section{Mobile Laser Scanning}

The term "mobile laser scanning" (MLS) means a laser scanning system is mounted on any moving platforms like vehicles or boats, except for the aircraft. The MLS system means that the laser scanning system is mounted on the top of a land-based vehicle (Lemmens, 2011). MLS has become a rapidly developing technology nowadays, especially for accurately mapping roads and building (Sun et al., 2018). As one of 3D data acquisition technologies, the MLS system not only has the advantages of TLS system characterized by high accuracy and point density, but also has advances in rapidly and cost-effectively capturing dense 3D point clouds for a large area. Although a variety of MLS systems have been built by diverse manufacturers, nearly all of them are based on navigation systems through integration of Global Navigation Satellite System (GNSS) and Inertial Measurement Unit (IMU) for directly obtaining geo-referenced LiDAR point clouds. As a contrast to possessing an ultra-high point density and spatial resolution, the point cloud of MLS has a relatively and evenly distributed point 
Ahmad Afiq Aiman Abdullah, Norzailawati Mohd Noor, Alias Abdullah, Maisarah Ali, Muhammad Hadi Mustafa

$3 D$ Geospatial Technique in Analysing the Malay Heritage Building Structures

density due to the movement of the scanning platform. Furthermore, multiple measurement stations are not mandatory when conducting a mobile laser scanning, so that the complex registration process can be avoided to some extent. Therefore, for further 3D analysis of large-scale urban scene especially for acquiring 3D dataset of street views and building facades, MLS is considered to be the primary choice (Sun et al. 2018).

\section{Malay Building Heritage}

Buildings have an immense effect on the lives of their users. In particular, houses are required to allocate spaces for individuals to feel safe, relaxed and satisfied to do what they desire, such as eating, sleeping, entertaining guests and many other functions based on their aspirations (Clements-Croome, 2006; Rapoport, 1990). The traditional Malay buildings such as palaces and religious building are originally adaptive design from the Malay house design and the variation of the building use, form and design changed due to change in the climatic and cultural factors. The traditional Malay building or Malay house was a timber house raise on stilt and basically a post and lintel structure with bamboo or wooden wall as façade design (Abdul Halim Nasir \& Wan Hashim Wan Teh, 1996). The Malay house evolved by the Malays over generation adapting the current needs, environment, climatic and also culture. Various of traditional and hybrid Malay houses form can be identified in Peninsular Malaysia and can be classified according to their roof shapes and the façade design.

\section{Characteristic of a Malay Roof}

There are a few basic roof forms being adaptive to the Malay house such as, bumbung panjang, bumbung limas, bumbung perak and bumbung lima. The most common one is the bumbung panjang or a long gable roof and believed that most of them are existed over a hundred years old (Abdul Halim Nasir \& Wan Hashim Wan Teh, 1996). According to Zumahiran (2015), the long-roofed house can be found in Northeast part of Malay Peninsula which are Kelantan and Terengganu which existed since 1800 s to 1920 s. The house has unique dwelling form with distinctive features and characteristic house.

\section{RESEARCH METHODOLOGY}

For the research methodology part, the initial phase was identifying the study area based on the historical data and literature review. The study area can be divided into two major elements which are the heritage building and the earliest Malay city in Malaysia. The data collection method based on one of the geospatial techniques which is using the laser scanning method. The use of laser scanning was mean to capture as much of data with less time consumed for the data collection. There are two laser scanning method being used for the paper which 
PLANNING MALAYSIA

Journal of the Malaysia Institute of Planners (2020)

are terrestrial laser scanning and mobile laser scanning. The main output data expected from the data collection was the point cloud-based data.

\section{Case Study}

For this paper, the selection of case study was two Malay royal town in Malaysia, Kota Bharu, Kelantan and Alor Setar, Kedah. Both of these study areas were amongst the earliest Malay city which were established since early 1700s and based on the sultanate ruling systems. Moreover, both of the study areas have unique similarity such as the relationship between the states with Siam, and free from British colonization until 1910. Besides, in term of the geographical and locational both of the palace as the city administrative centre which closed to the river estuary. Estuary towns such as Kota Bharu, Alor Star, Kuala Terengganu and Johor Baharu had already expanded and formed the early urbanisation of the Malay Peninsula and were referred to as Early Malay towns in Malaysia. Their status now remains as city states and conserved as heritage cities in Malaysia.

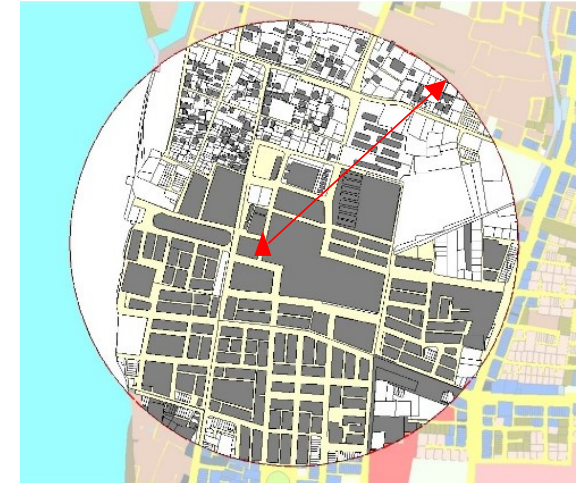

Figure 1(a) Study area Kota Bharu

$\Delta$ Istana Balai Besar Kota Bharu

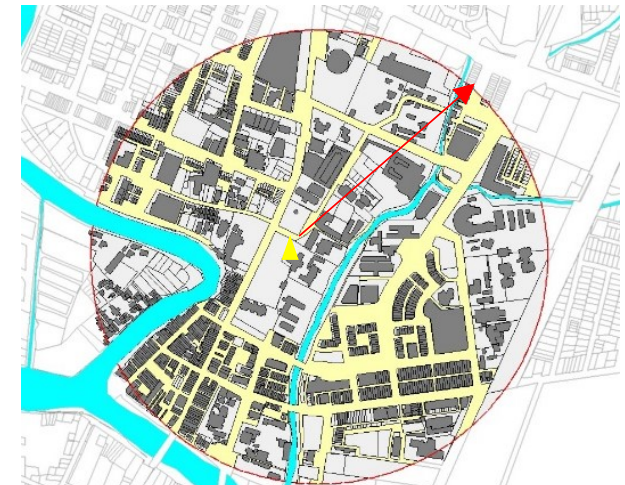

Figure 1(b) Study area Alor Setar Balai Besar Alor Setar

Figure 1 (a) and 1 (b) show the study areas which were selected within 500 meters from the centre where in this case, the palace has been identified as the centre for the study area. The establishment of Kota Bharu Kelantan as the Malay state has been started after the completion of Istana Balai Besar in 1845, while for Alor Setar, the completion of Istana Kota Setar and Balai Besar was in 1735 .

\section{DATA COLLECTION}

For the data collection, there are two laser scanning techniques being applied for both sites which are Terrestrial Laser Scanning and Mobile Laser Scanning. For TLS, data acquisition technique had been applied to the heritage building which are Istana Balai Besar Kelantan and Balai Besar Kedah, while on the other hand, 
Ahmad Afiq Aiman Abdullah, Norzailawati Mohd Noor, Alias Abdullah, Maisarah Ali, Muhammad Hadi Mustafa

3D Geospatial Technique in Analysing the Malay Heritage Building Structures

MLS was applied to the city area and settlement area which was identified earlier during the field survey that consists of Malay heritage building structure.

\section{Terrestrial Laser Scanning}

Capturing the data using the TLS required details planning before and during the data collection in order to capture the highest accuracy of data. For the Istana Balai Besar Kota Bharu, the TLS data acquisition was carried out using the Scan Station P40 laser scanner by Leica that offers highest versatility including long range capabilities during the scanning and data capturing process. This scanner is able to deliver highest quality 3D data and HDR imaging at an extremely fast scan rate of 1 million points per second at horizontal ranges of up to $270 \mathrm{~m}$ away from the scanner. The model used for the data collection process which involved two main procedures which are, laser scanning using P40 and photographing the textured images with the RGB values of the geometric object were captured by a high-resolution digital camera Nikon d3000.

There were 26 stations had been identified for the location of the scanner during scanning process. Besides the identification of the location and number of stations before scanning process, the target symbols are printed out in black and white colour on white paper before being pasted on the wall. Then, the symbols are circled around each of the scanning station and practically more than 5 targets placed around the 3D scan station to prepare the target for the scanning process. The target symbol is important to make sure the registering of the scanning data during the data processing stages. The placing of the target must meet the requirement of minimum 3 corresponding points in two different stations. This necessity was needed to smooth the post processing work. Besides, the numbers of total scan station depend on the size and complexity of the structure. Hence, appropriate scan station needs to be established for better coverage to cover all the details of the monument.

Meanwhile, for the Balai Besar Kedah, the TLS data acquisition was done using the GLS-2000 which has the $350 \mathrm{~m}$ maximum covering wide measuring range with scanning rate 120,000 point per second. The accuracy of this laser scanner is $3.5 \mathrm{~mm}$ at $150 \mathrm{~m}$ with built in 5 Megapixels camera. There are 29 stations identified before the scanning process. The selection of the stations was based on the overlapping area and visibility of the objects, which in this case were Balai Besar, Alor Setar. Each of the scan station's georeferenced coordinate was based on the GPS coordinate which transmitted via Global Navigation Satellite System (GNSS). All of the data scanned for the 29 stations are combined based on the coordinate data to become single point cloud data.

\section{Mobile Laser Scanning (MLS)}

For both of the study areas, for MLS technique, the scanner use was the TOPCON IP-S3 HD1 3D Mobile Mapping System. The selection the area for the MLS 
PLANNING MALAYSIA

Journal of the Malaysia Institute of Planners (2020)

scanning was based on the area within 500-meter radius from Istana Balai Besar Kelantan, and Balai Besar Kedah. For Kedah, the scanned area was along the Lebuhraya Darul Aman road and spread to the surrounding area within the radius. There are a few steps as shown in Figure 2 for the data collection of the mobile laser scanning process which are selection of the area and routes, kinetic calibrating, data collection, and final kinetic calibrating. The software used for the data collection was Magnet Master Field.

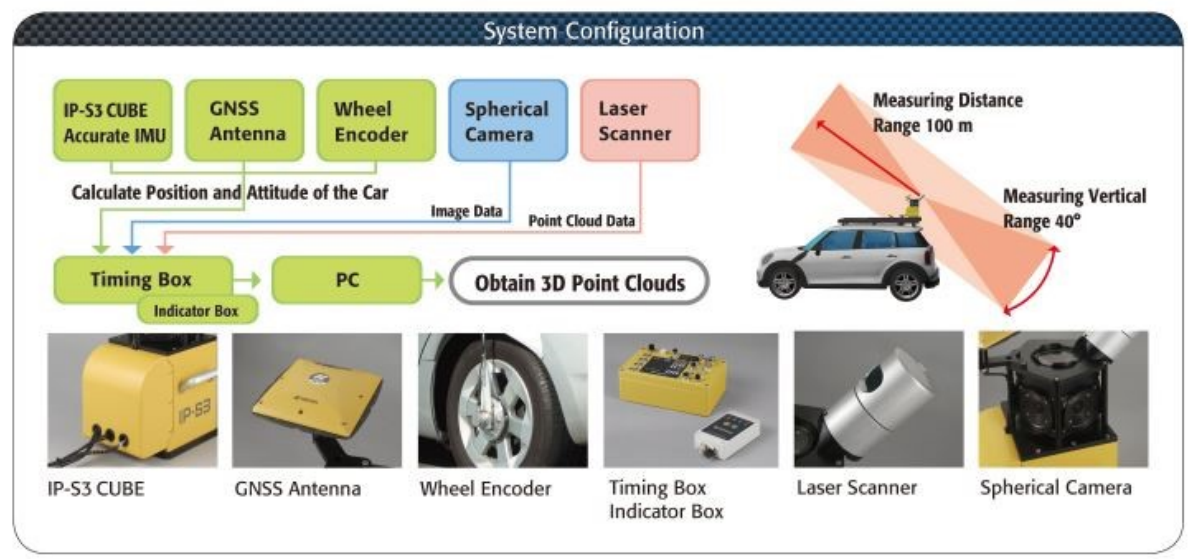

Figure 2. Data collection step for MLS

Collection of Ground Control point also has been carried out during the data collection. The RTK method was applied in collecting the GCP for each site during data collection. The GCP point contains the georeferenced coordinate and elevation of the control point which later will be used as the control point during the data processing. For Kota Bharu, there are 17 points, while there are 13 points for Alor Setar. The distribution of all points was based on the size of overall study area.

\section{RESULT AND ANALYSIS}

There are two main parts of finding in the paper, which are the point cloud produced from the TLS and point cloud produced by the MLS. Both techniques will undergo processing stages to produce the point cloud output dataset in. rcp format for further analysis. As one of the objectives in the paper is to recognize the building structured with Malay heritage element based on point cloud, the two elements from the data which are roof and façade of the building were emphasizes for the analysis. For the TLS data, the specific building has been identified as the heritage building which are Istana Balai Besar Kelantan and Balai Besar Kedah, while for the MLS data, the specific Malay Heritage building structure will be identified based on the point cloud database. 
Ahmad Afiq Aiman Abdullah, Norzailawati Mohd Noor, Alias Abdullah, Maisarah Ali, Muhammad Hadi Mustafa

3D Geospatial Technique in Analysing the Malay Heritage Building Structures

\section{Laser Scanning Result}

Based on the data acquisition using the MLS and TLS for Istana Balai Besar, Kelantan and Balai Besar Kedah, the point cloud data has been produced from the processing stages in. rcp format. The data can be open using Recap software which is one of the Autodesk software and can be used for detailed 3D modelling constructing in Revit software. From the recap software, the measurement and identification of the elements of the Malay heritage design can be identified and the point cloud data can be used as base for 3D reconstruction modelling and as information storage system of the form and design for existing heritage building structure.

Meanwhile, for MLS data from the data collection was processed using the Magnet Collage software to produce the output dataset point cloud in .rcp format. The point cloud data contains information of the georeferenced points, elevation and textured of the scanned object and the intensity of the scanned data. The intensity shows the ability of the laser beam to re-emit the laser data and converted into the data during the scanning process. From the Recap software, the data is analysed to recognize the heritage building structured that still exist for Kota Bharu and Alor Sear area. The determination of the building was based on the façade and roof design where the roof design for Kelantan House was based on 'bumbung panjang' roof design (Zumahiran, 2015). Figure 3 (a) and 3 (b) shows the MLS data in point cloud for Kota Bharu and Alor Setar.

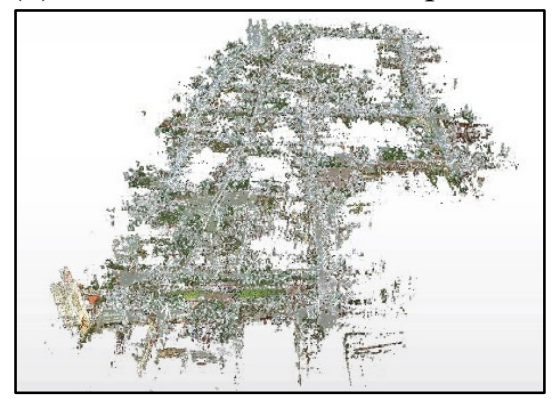

Figure 3 (a). Kota Bharu MLS Point Cloud

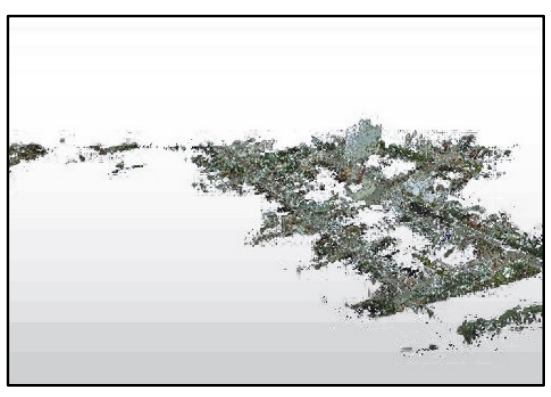

Figure 3 (b). Alor Setar MLS Point Cloud

\section{DATA ANALYSIS}

For the analysis part, there are a lot of analysis that can be produced by the point cloud database and the point cloud data one of the effective and comprehensive database especially in the heritage-based industries. The distance between each point up to millimetre unit give the high accuracy of the database. Besides, the ability of the points cloud database in stored the textured and georeferenced data also one of the salient points for data acquisition using the laser scanning technique. For the paper, the MLS data will be used in captured the form and 
PLANNING MALAYSIA

Journal of the Malaysia Institute of Planners (2020)

design of the structure for further reconstructing process of 3D model of the building. The data such as roof form, building height and element measurement will be analysed from the data. Meanwhile for the MLS dataset, the form, design and locational of the heritage Malay building will be analysed and extracted out based on the point cloud data.

\section{Laser scanning analysis}

The building form for study area in point cloud form from TLS, is analysed to be further used for detailed 3D modelling reconstruction using the Recap software for the elevation, façade design, unique motives and the measurement of the building. For detailed 3D model, this data was exported to the Revit software for detailed 3D modelling. Figure 3 (a) to 3 (d) show the example of analysis carried out from the point cloud data, where it involved the building elevation, structure and façade recognition and building measurement.

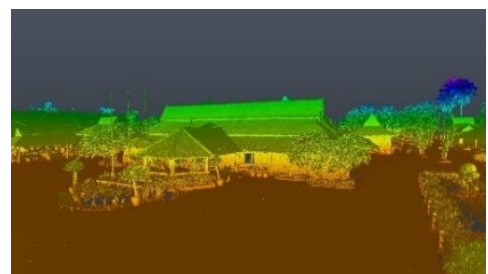

Figure 4 (a). Elevation data of Istana Balai Besar Kelantan

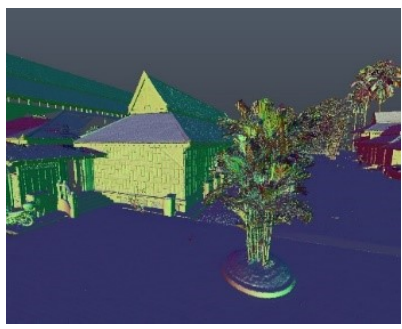

Figure 4 c). Janda Berhias façade design for Istana Balai Besar Kelantan

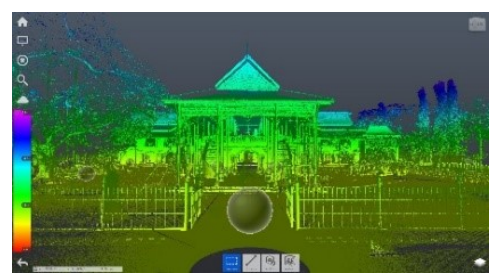

Figure 4 (b). Elevation data of Balai Besar Kedah

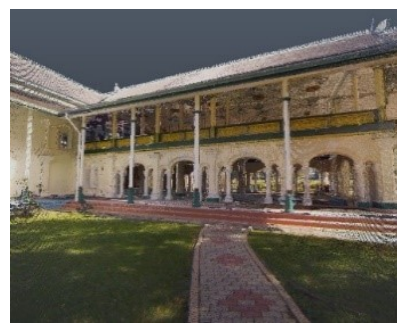

Figure 4 (d). Kerawang design at Balai Besar Kedah

Figure 4 (a) and 4 (b), shows the elevation analysis using the Recap file where each scanned point stored the elevation data offset from the mean sea level which captured during the scanning process. The elevation analysis represented by the colour intensity which varies according to the height range from $-5 \mathrm{~m}$ to $30 \mathrm{~m}$. From the elevation analysis, the floor level and roof based can be identified for the 3D modelling process. For Figure 4 (c) and 4 (d) the façade design, and motive design for both building can be analysed, where the design of "Janda Berhias" mounted on the facade Istana Balai Besar Kelantan and motive design 
Ahmad Afiq Aiman Abdullah, Norzailawati Mohd Noor, Alias Abdullah, Maisarah Ali, Muhammad Hadi Mustafa 3D Geospatial Technique in Analysing the Malay Heritage Building Structures

on the railing and column structure for Balai Besar Kedah which represent the Malay Architecture design.

Point cloud data from MLS different was compared to TLS due to technique and scanner's location during the data collection process. Synonym with the term "mobile", the positioning of the scanner mounted above a moving vehicle is able to capture the point cloud along the route taken by the vehicle with 360 degree of scanning object and image captured. The analysis on concentrated point cloud for Kota Bharu shows higher intensity than Alor Setar. This is due to the street network and land use arrangement in Kota Bharu are more compact compared to Alor Setar. Alor Setar faces higher development progress rate than Kota Bharu. In recognizing the building structured of Malay building, point cloud data was analysed based on the form and architecture design for the all scanned building. Figure 5 (a) to 5 (d) shows some of the roof structured and façade that shows the heritage Malay architecture design for the area.

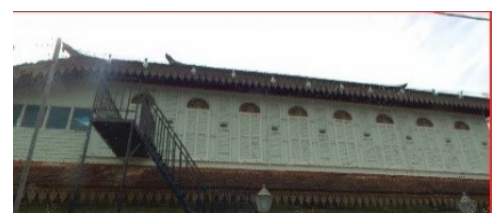

Figure 5 (a). Façade design for MAIK building, Kota Bharu

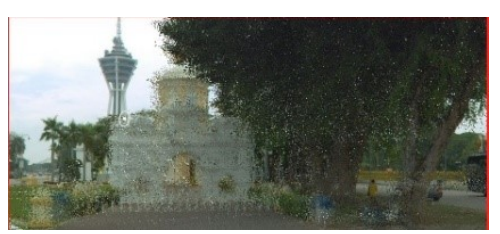

Figure 5 (c). Balai Nobat, Alor Setar

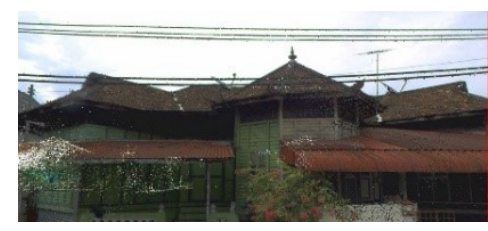

Figure 5 (b). Roof design for communal housing building in Kota Bharu

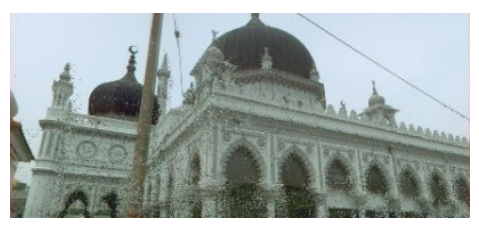

Figure 5 (d). Masjid Zahir, Alor Setar

\section{RESULT AND DISCUSSION}

The use of laser scanning technique was an effective method in data collection and can act as the effective medium for data information storage system. The ability of the producing the point cloud data with all the required information stored in each of the points was very helpful in data acquisition process and for data analysis. For both TLS and MLS method that has been carried out in this paper, both of the method achieved the main objective of the paper to recognize the Malay heritage building structure for both Kota Bharu and Alor Setar. From the TLS data analysis, both of the main buildings that are significant to the Malay city element was able to capture all the information needed to be used for further reconstructing of detailed 3D model using Revit software.

Meanwhile, using MLS method, it gave better result for Kota Bharu, as the study area still preserved most of the Malay heritage building such as, 
PLANNING MALAYSIA

Journal of the Malaysia Institute of Planners (2020)

Istana, Mosque and even the communal house. Based on the analysis, there are still buildings with structures that still preserve the Malay architecture which exist for almost more than 100 years old. For Alor Setar, the rapid development changes at the study area, resulted many original buildings had been demolished and replaced with the new building structure but still preserved for the main Malay city element such as palaces, mosque, street pattern and spaces for the main concentrated area in front of Balai Besar.

For Kota Bharu there are 71 buildings within the study area has been identified with the Malay element either on roof design or on the fade design, meanwhile for Alor Setar, there are only 15 buildings which still had the Malay identity and most of its were palaces. Differ with Kota Bharu, where the Malay design still can be detected even on the communal houses. This shows that, within the same radius, the development of Alor Setar was changing rapidly and most of the Malay houses were replaced with the modern buildings.

\section{CONCLUSION}

Malay buildings have a very unique and special characteristic with a unique architecture design, material use that compatible with the climatic condition, the roof form, motives design and the whole building structure that need to be preserve and capture for the data information of the building. This paper has identified the effective method in survey and data acquisition related to the recognizing the Malay heritage building structure for Kota Bharu and Alor Setar. Although TLS and MLS method were the only the tool used for data captured, but the process during the data scanning must be appropriate with the level of the data requirement, where the precise scanning process will provide more detailed and accurate dataset in point cloud. Besides, point cloud data which stored much of data type can be further explore for more analysis such as producing the flood prone area, and determine the shaded area from the nearby buildings.

\section{ACKNOWLEDGEMENTS}

The authors greatly acknowledged the International Islamic University of Malaysia for a research grant on Trans-Disciplinary Research Grant Scheme (TRGS/1/2016/UIAM/01/5/1), Ministry of Higher Education Malaysia for providing invaluable respective data used in this study.

\section{REFERENCES}

Abdul Halim Nasir \& Wan Hashim Wan Teh. (1996). The Traditional Malay House. Shah Alam, Selangor: Penerbit Fajar.

Chehata, N., Guo, L. and Mallet, C., (2009). Airborne Lidar Feature Selection for

Urban

Classification using Random Forest. In: Bretar F., Deseilligny M. and Vosselman, G. (Eds.), Laser Scanning 2009, IAPRS, 36 (3/ W8), Paris, France.

Beraldin, J.A \& Blais, François \& Lohr, Uwe. (2010). Three Dimensional Laser 
Ahmad Afiq Aiman Abdullah, Norzailawati Mohd Noor, Alias Abdullah, Maisarah Ali, Muhammad Hadi Mustafa

$3 D$ Geospatial Technique in Analysing the Malay Heritage Building Structures

Scanning

Technology.

Clements-Croome, D. (2006). Intelligent buildings: Design, Management and Operation. London, UK: Thomas Telford Publishing.

Guan, S., Trnka M. J., Bushnell, D. A., Robinson, P. J., Burlingame A. L (2015). Deconvolution Method for Specific and Nonspecific Binding of Ligand to Multiprotein Complex by Native Mass Spectrometry. Anal Chem 87(16):8541

Grussenmeyer \& Murtiyoso, Arnadi, Pierre \& Koehl, Mathieu \& Freville, Tristan. (2016). Acquisition and Processing Experiences of Close Range UAV Images for the 3D Modeling of Heritage Buildings. 10.1007/978-3-319-48496-9.

Haala, N., Peter, M., Cefalu, A. and Kremer, J., (2008). Mobile Lidar Mapping for Urban Data Capture. In: Loannides, Lemmens, M., 2011. Geo-information: Technology, Applications and the Environment, Geotechnologies and the Environment Series. Springer, (5): pp. 101-121.

Haddad, N. A., (2011). From ground surveying to 3D laser scanner: A review of techniques used for spatial documentation of historic sites. In Journal of King Saud University - Engineering Sciences, Vol. 23 (2), pp. 110.

Lee, S., Majid, Zulkepli \& Setan, Halim. (2013). 3D data acquisition for indoor assets using terrestrial laser scanning. ISPRS Annals of Photogrammetry, Remote Sensing and Spatial Information Sciences. II-2/W1. 221-226. 10.5194/isprsannalsII-2-W1-221-2013.

Lemmens, M., (2011). Geo-information: Technology, Applications and the Environment, Geotechnologies and the Environment Series. Springer, (5): pp. 101-121.

Nesi, L. (2013). The Use of 3D Laser Scanning Technology in Buildings Archaeology: The Case of Måketorpsboden in Kulturen Museum, Lund. Master's Thesis, Lund University, Lund, Sweden.

Rapoport, A. (1990). Defining vernacular design. In M. Turan (Ed.), Vernacular architecture paradigms of environmental response. Avebary: Gower Publishing Company Limited.

Sun, Z., Xu, Y., Hoegner, L. \& Stilla, U. (2018). Classification of MLS Point Clouds in Urban Scenes Using Detrended Geometric Features from Supervoxel

Ussyshkin, V., (2009). Mobile laser scanning technology for surveying application: from data collection to end-products. FIG Working Week 2009-Surveyors Key Role in Accelerated Development, Eilat, Israel, 3-8 May.

Zumahiran Kamaruddin. (2015). Long-roofed Houses of Northeatern Penisular Malaysia: Sustainability of Its Identity in the Built Environment. Procedia Environmental Sciences, Vol. 28.

Received: January 2020. Accepted: $1^{\text {st }}$ April 2020 